\title{
Utilização do milheto (Pennisetum glaucum (L.) R. Brown) grão na alimentação de suínos na fase inicial $(15-30 \mathrm{~kg} \text { de peso vivo })^{1}$
}

\author{
Utilization of pearl millet (Pennisetum glaucum (L.) R. Brown) grain on feeding of starting pigs
}

\author{
Alexandre Orio Bastos ${ }^{2}$ Ivan Moreira $^{3} \quad$ Alice Eiko Murakami $^{4} \quad$ Gisele Cristina de Oliveira $^{5}$ \\ Diovani Paiano $^{6}$ Mariane Kutschenko $^{6}$
}

\section{RESUMO}

\begin{abstract}
O objetivo deste trabalho foi avaliar a utilização do milheto (Pennisetum glaucum, (L.) R. Brown) na alimentação de suínos na fase inicial (15 aos $30 \mathrm{~kg}$ de peso vivo). Foi conduzido um experimento de desempenho, utilizando-se 48 leitões híbridos comerciais, sendo metade machos e metade fêmeas, com peso inicial de 14,9 $\pm 2,01 \mathrm{~kg}$. Utilizou-se a variedade IAPAR-IA98301 de milheto (MS: 90,61\%; PB: 11,64\%; Ca: 0,05\%, P: 0,29\% e

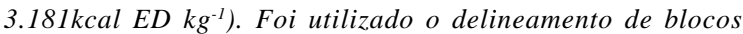
casualizados, com quatro tratamentos $(0,20,40$ e $60 \%$ de inclusão de milheto), seis repetições e dois animais por unidade experimental. A inclusão do milheto em rações para suínos na fase inicial não influenciou o consumo diário de ração, o ganho diário de peso, a conversão alimentar e o custo em ração por quilograma de suíno produzido. Em uma relação onde o preço do milheto corresponde a $70 \%$ do preço do milho, o custo em ração do quilograma de suíno produzido também não foi alterado. Os resultados sugerem que o milheto IAPAR-IA98301 pode ser incluído em rações de suínos na fase inicial até o nível de $60 \%$.
\end{abstract}

Palavras-chave: alimento alternativo, análise econômica, monogástricos, nutrição animal.

\section{ABSTRACT}

The objective of this study was to evaluate the pearl millet (Pennisetum glaucum (L.) R. Brown) utilization on feeding of initial pigs (15-30kg of body weight). A performance trial was conducted by using 48 crossbred pigs (a half barrows and a half females) with initial weight of $14.93 \pm 2.01 \mathrm{~kg}$ with the use of IAPAR-IA98301 species of pearl millet (DM 90.61\%; CP $11.64 \%$;

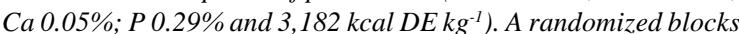
designwas used, with four treatments $(0 ; 20 ; 40$ and $60 \%$ of pearl millet inclusion), with six repetitions and two animals per experimental unit. The pearl millet inclusion on starting pigs diets did not influence on daily feed intake, average daily gain, feed:gain ratio and cost in diet per kilogram of pig produced during the initial phase. The results, suggest that the pearl millet IAPAR-IA98301 can be included in starting pig diets until $60 \%$.

Key words: alternative feed, animal nutrition, economic analysis, monogastrics.

\section{INTRODUÇÃO}

O elevado custo do milho e farelo de soja, constituintes tradicionais das rações de suínos no Brasil, sugere a necessidade de estudo de fontes alternativas a estes alimentos. O milheto em grão, em função do seu valor nutricional, vem sendo considerado como uma fonte viável nesta substituição.

O milheto em grão vem sendo testado como uma alternativa econômica, uma vez que produz boa quantidade de grãos em condições de deficiência hídrica, altas temperaturas, solos ácidos e com baixos índices de matéria orgânica. Apresenta ainda crescimento ótimo em curtos períodos de condições climatológicas favoráveis (ANDREWS \& KUMAR, 1992).

Por possuir teor de proteína superior ao do milho e sorgo, o milheto é considerado como bom alimento para monogástricos (ADEOLA \& ORBAN, 1995). Segundo BURTON et al. (1972), o milheto possui em média $12 \%$ de proteína, com variações de $8,8 \%$ a $20,9 \%$. Da mesma forma, o teor de aminoácidos do milheto

\footnotetext{
${ }^{1}$ Parte da Tese de doutorado do primeiro autor, parcialmente financiado pela Fundação ARAUCÁRIA.

2Zootecnista, Doutor, Ministério da Agricultura, Pecuária e do Abastecimento, PR.

${ }^{3}$ Zootecnista, Doutor, Pesquisador do Conselho Nacional de desenvolvimento Científico e Tecnológico (CNPq). Professor Titular, Departamento de Zootecnia da Universidade Estadual de Maringá (UEM). (Av. Colombo, 5790, 87020-900, Maringá, PR). E-mail: imoreira@uem.br. Autor para correspondência.

${ }^{4}$ Zootecnista, Doutor, Pesquisador do CNPq, Professor Titular, Departamento de Zootecnia, UEM.

${ }^{5}$ Zootecnista, Mestre em Zootecnia.

${ }^{6}$ Zootecnista, Alunos do Curso de Mestrado de Zootecnia, UEM.
} 
é superior ao sorgo e ao milho e comparável a outros pequenos grãos, como a cevada e o arroz (EJETA et al. 1987). Valores superiores de lisina, metionina e treonina, três dos principais aminoácidos para os suínos, foram reportados por ADEOLA \& ORBAN (1995)

Embora tenha energia bruta superior, a concentração de energia digestível para suínos é cerca de $15 \%$ inferior a do milho (VIANA, 1982). Valor de energia digestível de $3.080 \mathrm{kcal} /$ $\mathrm{kg}$, foi obtido por FIALHO et al. (1999). O menor valor de energia digestível para o milheto torna necessária a inclusão de óleos e gorduras, na formulação da ração, podendo torná-lo, do ponto de vista econômico, um substituto parcial do milho. Entretanto, tal aumento de custo pode ser minimizado pelo maior teor protéico e melhor perfil de aminoácidos do milheto, o que diminui a utilização de concentrados protéicos de maior custo, quando comparado com o concentrado energético (YAVDAV et al., 1990). Outro fator a ser considerado é o menor custo do milheto, quando comparado ao milho, principalmente, no período de entressafra.

Em trabalhos com suínos até $25 \mathrm{~kg}$, utilizando rações não isoenergéticas, com diferentes níveis de substituição de milho por milheto $(0,25,50,75$ e 100\%), LAWRENCE et al. (1995), observaram um efeito quadrático para ingestão diária de ração. O ponto máximo de ingestão ocorreu quando da utilização de $50 \%$ de milheto, sendo que, até a substituição total, não foram observados efeitos negativos sobre o desempenho.

O crescimento da cultura de milheto no Brasil e os resultados satisfatórios com a utilização do grão de milheto na alimentação animal despertaram o interesse de empresas produtoras de sementes para o desenvolvimento de novas variedades. O Instituto Agronômico do Paraná (IAPAR) trabalha no desenvolvimento de uma nova variedade, a IAPAR-IA98301, que em estudos preliminares (BASTOS et al., 2001), apresentou melhores valores de energia digestível que as demais variedades. Por isso, a utilização de rações à base de milheto, pode representar uma redução nos níveis de inclusão de óleos.

O objetivo deste trabalho foi o de determinar a viabilidade nutricional e econômica da utilização do milheto IAPAR na alimentação de suínos na fase inicial de crescimento.

\section{MATERIAL E MÉTODOS}

O experimento foi conduzido no Setor de Suinocultura da Fazenda de Experimental de Iguatemi, da Universidade Estadual de Maringá (UEM).

As baias experimentais eram elevadas, sendo 2/3 de piso cimentado e 1/3 de piso de plástico vazado, equipadas com bebedouro tipo chupeta e comedouro tipo calha. Os animais receberam ração e água à vontade.

O milheto utilizado foi o IAPAR-IA98301, variedade em desenvolvimento pelo IAPAR cuja composição química e energética está expressa na tabela 1. O peso de 1000 grãos do milheto, que representa a massa do grão, foi de 17,8g.

As rações utilizadas (Tabela 2) foram isoenergéticas, isolisínicas e formuladas, procurando atender às exigências nutricionais do NRC (1998).

Os dados de consumo de ração e ganho de peso foram coletados a cada duas semanas e, a partir destes dados, calculou-se a conversão alimentar no período considerado.

Tabela 1 - Composição química, energética, de aminoácidos e valores digestíveis do milheto IAPAR (IA98301)

\begin{tabular}{lc}
\hline \multicolumn{1}{c}{ Itens } & \multicolumn{1}{c}{ Milheto IAPAR } \\
\hline \multicolumn{2}{c}{ Composição química e energética ${ }^{2}$} \\
\hline Matéria seca, \% & 86,73 \\
Proteína bruta, \% & 11,64 \\
Energia bruta, kcal/kg & 4.445 \\
Energia digestível, kcal/kg ${ }^{3}$ & 3.181 \\
Extrato etéreo, \% & 4,23 \\
Fibra bruta, \% & 1,61 \\
FDN, \% & 12,12 \\
FDA, \% & 3,81 \\
Amido, \% & 76,36 \\
Cinzas, \% & 1,79 \\
Cálcio, \% & 0,05 \\
Fósforo, \% & 0,29 \\
\hline & \\
Composição de aminoácidos (valores na matéria natural) ${ }^{4} \%$ \\
\hline Lisina & 0,307 \\
Metionina & 0,209 \\
Metionina+ cistina & 0,389 \\
Treonina & 0,438 \\
Arginnina & 0,520 \\
Glicina+ serina & 0,932 \\
Isoleucina & 0,462 \\
Valina & 0,585 \\
Leucina & 1,154 \\
Histidina & 0,245 \\
Fenilalanina & 0,561 \\
Fenilalanina+ tirosina & 0,837 \\
\hline
\end{tabular}

1 - Variedade de milheto desenvolvida pelo Instituto Agronômico do Paraná - IAPAR; 2 - Valores determinados no Laboratório de Nutrição Animal da UEM; 3 - Foi considerado o coeficiente de digestibilidade de 71,57\%, determinado anteriormente por BASTOS et al. (2001), para esta mesma variedade de milheto; 4 Analisado pela AJINOMOTO. 
Tabela 2 - Composição percentual, energética e química das rações experimentais

\begin{tabular}{|c|c|c|c|c|}
\hline \multirow{2}{*}{ Itens } & \multicolumn{4}{|c|}{ Níveis de inclusão de milheto, \% } \\
\hline & 0 & 20 & 40 & 60 \\
\hline \multicolumn{5}{|c|}{ Ingredientes, \% } \\
\hline Milho & 73,65 & 53,51 & 33,48 & 13,45 \\
\hline Milheto IAPAR ${ }^{1}$ & - & 20,00 & 40,00 & 60,00 \\
\hline Farelo de soja & 23,43 & 22,32 & 21,17 & 20,03 \\
\hline Óleo de soja & 0,00 & 1,36 & 2,39 & 3,55 \\
\hline Suplemento vitamínico e mineral ${ }^{2}$ & 0,50 & 0,50 & 0,50 & 0,50 \\
\hline Sal & 0,35 & 0,35 & 0,35 & 0,35 \\
\hline L-lisina $\mathrm{HCl}$ & 0,099 & 0,117 & 0,135 & 0,153 \\
\hline Calcário calcítico & 0,60 & 0,61 & 0,62 & 0,63 \\
\hline Fosfato bicálcico & 1,38 & 1,36 & 1,34 & 1,33 \\
\hline \multicolumn{5}{|c|}{ Nutrientes (Valores calculados) } \\
\hline Energia digestível, kcal/kg & 3.366 & 3.370 & 3.370 & 3.370 \\
\hline Cálcio, \% & 0,67 & 0,67 & 0,67 & 0,67 \\
\hline Fósforo total, \% & 0,57 & 0,57 & 0,57 & 0,57 \\
\hline Lisina total, \% & 1,03 & 1,03 & 1,03 & 1,03 \\
\hline Metionina+cistina total, \% & 0,57 & 0,57 & 0,57 & 0,57 \\
\hline Treonina total, \%) & 0,66 & 0,66 & 0,67 & 0,67 \\
\hline Triptofano total, \% & 0,20 & 0,20 & 0,21 & 0,22 \\
\hline
\end{tabular}

${ }^{1}$ Variedade de milheto desenvolvida pelo Instituto Agronômico do Paraná - IAPAR;

${ }^{2}$ Suplemento vitamínico e mineral (quantidade por kg de ração): Vit. A - 10.000 UI; Vit. D3 - 2.000 UI; Vit. E - 25,0 UI; Vit K3 -30,0 mg; Ác. Pantotênico - 12,0 mg; Biotina- 0,1 mg; Ác. Fólico- 1,0 mg; Selênio- 0,3 mg; Colina- 150,0 mg; Lisina- 1.170,0 mg; Promotor de crescimento - 50,0 mg; Antioxidante - 100 mg; Iodo- 1,5 mg; Cobalto - 1,0 mg; Cobre - 175,0 mg; Zinco - 100,0 mg; Ferro - 100,0 mg; Manganês - 40,0 mg.

Foi feita a análise da eficiência econômica da utilização do milheto em cada um dos tratamentos sobre o desempenho de suínos. Esta eficiência foi analisada através da estimativa do custo em ração por quilograma suíno produzido, do Índice de Eficiência Econômica (determinado pela razão entre o menor custo médio e o custo médio do tratamento considerado, multiplicado por cem) e do Índice do Custo Médio (determinado pela razão entre o custo médio do tratamento e o menor custo médio multiplicado por cem). Foram utilizadas as formulas descritas por BELLAVER et al. (1985) e BARBOSA et al. (1992).

Os preços dos insumos utilizados na elaboração dos custos foram: milho R $\$ 0,153 / \mathrm{kg}$; milheto R\$ 0,1071/kg; farelo de soja R\$ 0,48/kg; oleo de soja R\$ 0,90/kg; fosfato bicálcico R\$ 0,68/ kg; calcário calcítico calcítico R \$ 0,06/kg; suplemento mineral e vitamínico inicial R\$ 6,39/ kg; L-lisina R\$ 5,53/kg; sal R\$ 0,28/kg.

O delineamento experimental utilizado foi o de blocos inteiramente casualizados, com quatro tratamentos e seis blocos e dois animais por unidade experimental. Os tratamentos experimentais consistiram de quatro níveis de inclusão de milheto $(0,20,40$ e $60 \%)$ na ração. Cada unidade experimental foi representada por uma baia contendo dois animais (um macho e uma fêmea). Foram utilizados 48 suínos, híbridos comerciais, sendo metade machos castrados e metade fêmeas, com peso médio inicial de 14, $9 \pm$ $2,01 \mathrm{~kg}$.

As variáveis de consumo diário de ração, ganho diário de peso, conversão alimentar e custo em ração por quilograma de suíno produzido foram submetidas à análise de regressão polinomial, utilizando o programa SAEG (UFV, 1997), de acordo com o seguinte modelo estatístico:

$Y_{i j}=m+b_{1}\left(A_{i}-A\right)+b_{2}\left(A_{i}-A\right)+B_{j}+e_{i k}$ onde: $\mathrm{Y}_{\mathrm{ij}}=$ Valor observado da variável estudada, relativo ao nível i de milheto, no bloco $\mathrm{j}$;

$\mathrm{m}$ = média geral;

$\mathrm{b}_{1}=$ coeficiente de regressão linear da variável y, em função dos níveis de inclusão de milheto nas rações;

$\mathrm{b}_{2}=$ coeficiente de regressão quadrático da variável y, em função dos níveis de inclusão de milheto nas rações;

$\mathrm{A}=$ nível de inclusão de milheto $\mathrm{i}$, para $\mathrm{i}=0,20$, 40 e $60 \%$;

$\mathrm{A}=$ nível médio (30\%) de inclusão de milheto às rações;

$\mathrm{B}_{j}=$ efeito do $j_{\text {ésimo }}$ bloco $(j=1,2,3,4,5$ e 6$)$; e $\mathrm{e}_{i j}=$ erro aleatório associado a cada observação.

Ciência Rural, v.34, n.6, nov-dez, 2004. 


\section{RESULTADOS E DISCUSSÃO}

Os resultados de consumo diário de ração, ganho diário de peso e conversão alimentar de suínos, na fase inicial, alimentados com níveis crescentes de inclusão de milhetos, estão apresentados na tabela 3. A inclusão de até $60 \%$ de milheto IAPAR-IA98301 não influenciou $(\mathrm{P}>0,05)$ o consumo diário de ração, 0 ganho diário de peso e a conversão alimentar.

Dados apresentados por LAWRENCE et al. (1995), com a substituição de até 100\% do milho pelo milheto em suínos com até $25 \mathrm{~kg}$ de peso vivo, mostram que o ganho diário de peso não se alterou, sendo observado apenas aumento linear no consumo diário de ração. Este aumento no consumo diário de ração foi justificado pelo não ajuste dos níveis energéticos na ração, pois, como o milheto apresenta menor teor de energia digestível do que o milho, houve redução linear nos níveis energéticos na ração, tornando necessário maior consumo para atender à demanda de energia digestível. No presente experimento, o não aumento no consumo não era esperado, uma vez que o nível energético das rações foi mantido constante por meio da adição de óleo vegetal.

A utilização de milheto, em outras fases de produção, tem mostrado comportamento similar, ou seja, não reduz o desempenho dos suínos, podendo promover melhoria em alguns casos. Trabalhando com diferentes níveis de substituição do milho pelo milheto $(0,25,50$, 75 e 100\%), em suínos na fase de crescimento, NUNES et al. (1997) não observaram redução no desempenho, resultados estes similares aos obtidos por BANDEIRA et al. (1996), que utilizaram os mesmos níveis de substituição ao milho para suínos em terminação.
Em estudo com cinco diferentes níveis de inclusão de milheto $(0,15,30$, 45 e $60 \%)$ nas fases de crescimento ou terminação, BASTOS et al. (2002), não observaram diferença no desempenho dos suínos na fase de crescimento. Entretanto, ao analisar o período total, observaram efeito quadrático para o desempenho, sendo o maior ganho de peso proporcionado com a inclusão de $36,02 \%$ de milheto. Isto sugere que a utilização do milheto, por um período maior, pode melhorar o desempenho de suínos.

O milheto IAPAR-IA98301, utilizado no presente experimento, pode ser considerado do ponto de vista nutricional, equivalente às outras variedades já testadas, como a comum e a BN2, e representa uma alternativa em substituição ao milho, pois níveis de inclusão de até $60 \%$ de milheto (Tabela 3) não pioraram o desempenho dos suínos dos 15 aos 30kg de peso vivo.

Os resultados da análise econômica com a utilização de níveis crescentes de inclusão de milheto em rações para suínos dos 15 aos $30 \mathrm{~kg}$ estão apresentados na tabela 4. O custo em ração por quilograma de suíno produzido, considerando a relação do preço do milheto em $70 \%$ do preço do milho, não diferiu $(\mathrm{P}>0,05)$ com a inclusão de até $60 \%$ de milheto. Apesar disso, pode ser observado que o índice de custo médio mostra que o acréscimo de $60 \%$ de milheto representou redução numérica $(P>0,05)$ de 5,26\% no custo em ração por quilograma de suíno produzido.

Como não foi observado efeito da inclusão do milheto às rações, sobre as características de desempenho dos suínos na fase inicial e, como o custo do quilograma de ração diminuiu à medida que se aumentou o nível de inclusão do milheto nas rações,

Tabela 3 - Desempenho de suínos na fase inicial, alimentados com rações, contendo níveis crescentes de inclusão de milheto IAPAR (IA98301)

\begin{tabular}{|c|c|c|c|c|c|c|c|}
\hline \multirow{2}{*}{ Item } & \multicolumn{4}{|c|}{ Níveis de inclusão de milheto, \% } & \multicolumn{3}{|c|}{ Análise de variância } \\
\hline & 0 & 20 & 40 & 60 & Média & $\mathrm{CV}^{1}, \%$ & Efeito \\
\hline \multicolumn{8}{|c|}{0 a 14 dias } \\
\hline Peso inicial, kg & 14,78 & 14,92 & 14,83 & 15,18 & 14,93 & - & - \\
\hline Consumo diário de ração, kg & 1,01 & 0,98 & 0,97 & 1,07 & 1,01 & 10,27 & $\mathrm{NS}^{2}$ \\
\hline Ganho diário de peso, kg & 0,610 & 0,592 & 0,573 & 0,635 & 0,603 & 12,11 & NS \\
\hline Conversão alimentar & 1,65 & 1,67 & 1,69 & 1,68 & 1,67 & 6,97 & NS \\
\hline \multicolumn{8}{|l|}{0 a 28 dias } \\
\hline Consumo diário de ração, kg & 1,26 & 1,27 & 1,22 & 1,29 & 1,26 & 8,37 & NS \\
\hline Ganho diário de peso, kg & 0,661 & 0,678 & 0,656 & 0,671 & 0,667 & 6,61 & NS \\
\hline Conversão alimentar & 1,90 & 1,86 & 1,87 & 1,92 & 1,89 & 5,74 & NS \\
\hline Peso final, kg & 33,71 & 34,34 & 33,61 & 33,95 & 33,90 & 5,91 & NS \\
\hline
\end{tabular}

${ }^{1}$ Coeficiente de variação,

Não significativo ( $\mathrm{P}>0,05)$.

Ciência Rural, v.34, n.6, nov-dez, 2004. 
Tabela 4- Custo do quilograma de ração, custo em ração por quilograma de suíno produzido (CR), índice de eficiência econômica (IEE) e índice de custo médio (IC) para suínos em fase inicial alimentados com níveis crescentes de inclusão de milheto IAPAR (IA98301)

\begin{tabular}{|c|c|c|c|c|c|c|}
\hline \multirow[t]{2}{*}{ Item } & \multicolumn{4}{|c|}{ Níveis de inclusão do milheto (\%) } & \multirow{2}{*}{$\mathrm{CV}^{1}, \%$} & \multirow{2}{*}{ Efeito } \\
\hline & 0 & 20 & 40 & 60 & & \\
\hline Custo da ração ${ }^{2}, \mathrm{R} \$ / \mathrm{kg}$ & 0,301 & 0,299 & 0,295 & 0,291 & - & - \\
\hline CR, R\$/kg PV ganho & 0,570 & 0,557 & 0,551 & 0,540 & 8,92 & $\mathrm{NS}^{3}$ \\
\hline IEE & 95,70 & 97,11 & 98,39 & 100 & - & - \\
\hline IC & 105,56 & 103,16 & 102,02 & 100 & - & - \\
\hline
\end{tabular}

${ }^{1}$ Coeficiente de variação.

${ }^{2}$ Custos baseados em uma relação de preços para o milheto de $70 \%$ do valor (R\$) do milho.

${ }^{3}$ Não significativo $(\mathrm{P}>0,05)$.

pode-se admitir que, nestas condições de preço estudadas, a inclusão de $60 \%$ de milheto mostrou ser o melhor em termos econômicos.

Os resultados deste experimento mostram que o milheto é uma alternativa ao milho na elaboração de rações para suínos na fase inicial, desde que se faça a correção da energia e da lisina. Portanto, a opção para sua utilização fica na dependência da relação de preços com o milho e o farelo de soja.

\section{CONCLUSÕES}

O milheto IAPAR-IA98301 pode ser incluído em rações de suínos na fase inicial até o nível de $60 \%$.

\section{AGRADECIMENTOS}

Agradecimentos são dirigidos à FUNDAÇÃO ARAUCÁRIA e ao INSTITUTO AGRONÔMICO DO PARANÁ (IAPAR), pela colaboração na condução da pesquisa.

\section{REFERÊNCIAS BIBLIOGRÁFICAS}

ADEOLA, O.; ORBAN, J.I. Chemical composition and nutrient digestibility of pearl millet (Pennisetum glaucum) fed to growing pigs. Journal of Cereal Science, v.22, p.177184, 1995.

ANDREWS, D.J.; KUMAR, K.A. Pearl millet for, food, feed and forage. Advances in Agronomy, v.48, p.89-139, 1992.

BANDEIRA, M.N. et al. Utilização do milheto grão como substituto do milho em rações para suínos na fase de terminação. Arquivos das Escolas de Agronomia e Veterinária da Universidade Federal de Goiás, Goiânia, v.26, n.2, p.57-64, 1996.

BARBOSA, H.P. et al. Trighilho para suínos nas fases inicial, crescimento e terminação. Revista da Sociedade Brasileira de Zootecnia, v.21, n.05, p.827-837, 1992.

BASTOS, A.O. et al. Utilização de diferentes níveis de grão de milheto (Pennisetum glaucum (L.) R. Brown) na alimentação de suínos. Revista da Sociedade Brasileira Zootecnia, v.31, n.04, p1753-1760, 2002.
BASTOS, A.O. et al. Digestibilidade de diferentes tipos de milheto (Pennisetum Glaucum (L.) R. Brown) em suínos. In : REUNIÃO ANUAL DA SOCIEDADE BRASILEIRA DE ZOOTECNIA, 38., 2001, Piracicaba. Anais... São Paulo : ZBZ/ FEALQ, 2001. p.792-793.

BELLAVER, C. et al. Radícula de malte na alimentação de suínos em crescimento e terminação. Pesquisa Agropecuária Brasileira, v.20, n.8, p.969-974, 1985.

BURTON, G.W.; WALLACE, A.T.; RACHIE, K.O. Chemical composition and nutritive value of pearl millet (Pennisetum typhoyde) grain. Crop Science, v.12, p.187, 1972.

EJETA, G.; HANSEN, M.M.; MERTZ, E.T. In vitro digestibility and amino acid composition of pearl millet (Pennisetum typhoides) and others cereals. Proceedings of National Academy of USA, v.84, p.6016-6019,1987.

FIALHO, E.T. et al. Uso de ensaios de metabolismo para determinação dos valores nutricionais de alguns alimentos com suínos. In: REUNIÃO ANUAL DA SOCIEDADE BRASILEIRA DE ZOOTECNIA, 36., 1999, Porto Alegre. Anais... São Paulo : Sociedade Brasileira de Zootecnia/Gmosis, 1999. CD-ROM. Nutrição animal. Nutrição de Não Ruminantes. NUN115.

LAWRENCE, B.V.; ADEOLA, O.; ROGLER, J.C. Nutrient digestibility and growth performance of pigs fed pearl millet as a replacement for corn. Journal of Animal Science, v.73, n.7, p.2026-2032, 1995.

National Research Council - NRC. Nutrients Requirements of Swine. 10.ed. Washington, DC : National Academic, 1998. 189p.

NUNES, R.C. et al. Utilização do milheto grão como substituto do milho em rações para suínos na fase de crescimento. Arquivos das Escolas de Agronomia e Veterinária da Universidade Federal de Goiás, Goiânia, v.27, n.2, p.41-48, 1997.

UNIVERSIDADE FEDERAL DE VIÇOSA - UFV. SAEG Sistemas de análises estatísticas e genéticas. Versão 7.1. Viçosa, MG: UFV, 1997. 150p. (Manual do usuário)

VIANA, S.P. Utilização de milheto em rações para aves e suínos como alternativa energética para algumas regiões do semi-árido. In: CULTURA do milheto. Fortaleza : Empresa Pernambucana de Pesquisa Agropecuária, 1982. p.59-63. (Monografias, 8)

YAVDAV, B.P.S.; VARMA, A.; GUPTA, J.J. Utilization of green bajra (Pennisetum americanum) fodder in pig rations. Indian Journal of Animal Nutrition, v.7, n.4, p315-316, 1990. 